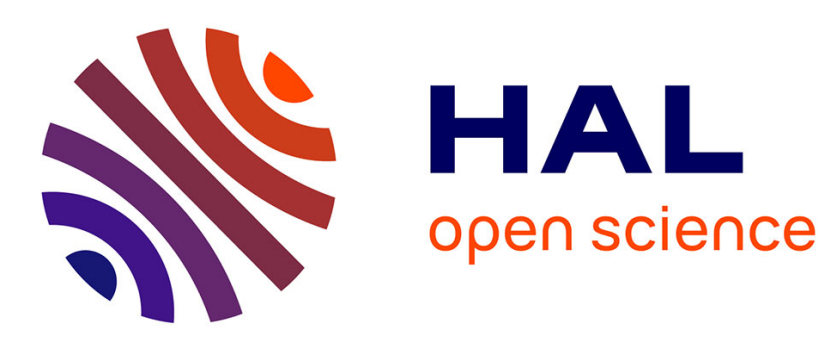

\title{
The environment and directed technical change: comment
}

\author{
Jean Charles Hourcade, Antonin Pottier, Etienne Espagne
}

\section{To cite this version:}

Jean Charles Hourcade, Antonin Pottier, Etienne Espagne. The environment and directed technical change : comment. 2011. hal-00866435

\section{HAL Id: hal-00866435 \\ https://hal.science/hal-00866435}

Preprint submitted on 30 Sep 2013

HAL is a multi-disciplinary open access archive for the deposit and dissemination of scientific research documents, whether they are published or not. The documents may come from teaching and research institutions in France or abroad, or from public or private research centers.
L'archive ouverte pluridisciplinaire HAL, est destinée au dépôt et à la diffusion de documents scientifiques de niveau recherche, publiés ou non, émanant des établissements d'enseignement et de recherche français ou étrangers, des laboratoires publics ou privés. 


\section{DOCUMENTS DE TRAVAIL / WORKING PAPERS}

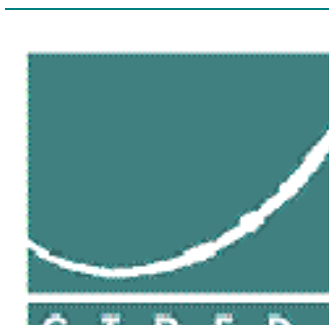

C.I.R.E.D.

No 36-2011

The environment and directed technical change: comment

Jean-Charles Hourcade

Antonin Pottier

Etienne Espagne

November 2011

\section{CIRED Working Papers Series}

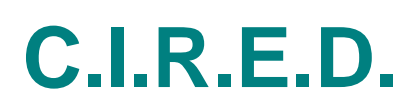

Centre International de Recherches sur l'Environnement et le Développement

UMR 8568 CNRS / EHESS / ENPC / ENGREF

/ CIRAD / METEO FRANCE

45 bis, avenue de la Belle Gabrielle

F-94736 Nogent sur Marne CEDEX

Tel : (33) 143947373 / Fax : (33) 143947370

www.centre-cired.fr 
CIRED Working Papers Series 


\begin{abstract}
This paper discusses the growth model with environmental constraints recently presented in (Acemoglu et al., 2011) which focuses on the redirection of technical change by climate policies with research subsidies and a carbon tax. First, Acemoglu et al.'s model and chosen parameters yield numerical results that do not support the conclusion that ambitious climate policies can be conducted " without sacrificing (much or any) long-run growth ». Second, they select unrealistic key parameters for carbon sinks and elasticity of substitution. We find that more realistic parameters lead to very different results. Third, the model leads to an unrealistic conclusion when used to analyse endogenous growth, suggesting specification problems.
\end{abstract}

Keywords: technological change, endogenous growth, climate change, energy substituability

\title{
Résumé
}

Cet article analyse le modèle de croissance sous contraintes environnementales présenté par Acemoglu et al. (2011), lequel met l'accent sur la réorientation du changement technique au moyen de politiques climatiques combinant une taxe carbone et des subventions à la recherche. En premier lieu, le modèle de Acemoglu et al. avec les paramètres retenus fait ressortir des résultats numériques qui ne soutiennent nullement la conclusion selon laquelle des politiques climatiques ambitieuses peuvent être conduites "sans (guère ou pas du tout) sacrifier la croissance de long terme ". Par ailleurs, Acemoglu et al. ont choisi des valeurs irréalistes pour des paramètres cruciaux comme les puits de carbone ou l'élasticité de substitution. Des valeurs plus réalistes donnent des résultats très différents. En troisième lieu, utilisé pour analyser la croissance endogène, le modèle aboutit à des incohérences, ce qui suggère des problèmes de spécification.

Mots-clés : modèle de croissance, politique climatique, transition technologique, taxe carbone, puits de carbone 
CIRED Working Papers Series 


\title{
The environment and directed technical change: comment
}

\author{
Jean-Charles Hourcade*, Antonin Pottier ${ }^{\dagger}$, Etienne Espagne ${ }^{\ddagger}$ \\ CIRED
}

November 2011

\begin{abstract}
This paper discusses the growth model with environmental constraints recently presented in (Acemoglu et al., 2011) which focuses on the redirection of technical change by climate policies with research subsidies and a carbon tax. First, Acemoglu et al.'s model and chosen parameters yield numerical results that do not support the conclusion that ambitious climate policies can be conducted "without sacrificing (much or any) long-run growth". Second, they select unrealistic key parameters for carbon sinks and elasticity of substitution. We find that more realistic parameters lead to very different results. Third, the model leads to an unrealistic conclusion when used to analyse endogenous growth, suggesting specification problems.
\end{abstract}

Keywords: technological change, endogenous growth, climate, energy substituability

Acemoglu et al. (2011) include "endogenous and directed technical change in a growth model with environmental constraints and limited resources" in order to provide "a systematic framework of the impact of different types of environmental regulations on the direction of technical change". They conclude that a dual policy involving carbon taxation and research subsidies is superior to a policy based only on a carbon price, and we agree with this conclu$\operatorname{sion}^{1}$. However they also suggest that successful mitigation "policies only need to be in place for a temporary period" and "without sacrificing (much or any) long-run growth".

But a precise examination of the model results reveals a gap between these claimed conclusions and the numerical results. This gap is large enough to raise three sets of interlinked questions, first about the interpretation of the results, second about the parameter choices, and third about structural problems of the AABH model. We discuss these points in order.

\footnotetext{
${ }^{*}$ Head of CIRED (International Centre of Research in Environment and Development), hourcade@centre-cired.fr

${ }^{\dagger}$ CIRED searcher, pottier@centre-cired.fr, corresponding author

${ }^{\ddagger}$ CIRED searcher, espagne@centre-cired.fr

${ }^{1}$ Conclusion derived by the three last IPCC reports (Hourcade et al., 1995, 2001; Gupta et al., 2007). For recent contributions, see (Fischer and Newell, 2008; Gerlagh, 2008; Schmidt and Marschinski, 2009).
} 


\section{Interpretative problems about numerical results}

In the $\mathrm{AABH}$ economy, two intermediate goods $Y_{j}$, a clean one $j=c$ and a dirty one $j=d$, are used to produce a unique final good $Y$ through a constant elasticity of substitution $(\epsilon)$ production function. The dynamics of production are governed by productivity factors $A_{j}$ in each sector. The growth rate of these $A_{j}$ is the product of the (normalized) number of researchers $s_{j}$ dedicated to producing innovations in sector $j$ and of an identical maximum growth rates $\gamma \eta_{j}=2 \%$. These $A_{j}$ are calibrated so that the volumes of the dirty and clean intermediate goods equate to the total of fossil and non fossil world primary energy supply given by world energy balances. The AABH model calculates the evolution of this economy under laissez-faire and with an optimal policy mix in the presence of a climate externality caused by the dirty good. GDP departures from a maximum $2 \%$ growth rate under laissezfaire are generated when the combination of an innovation subsidy and a carbon tax spur the productivity of the clean sector and cause the final producer to use more of the still less productive clean technology. GDP departures last as long as the productivity of this technology has not caught up the productivity of the dirty one.

Acemoglu et al. conduct three numerical experiments with two different elasticities of substitution between the clean and dirty good $\epsilon=3,10$. The interpretative problem about the modeling results concerns the statement that "excessive use of carbon taxes can be avoided". The article does not give the level of the assumed taxes but, after programming the same model, we found that, with $\epsilon=3$ and $\rho=0.015$, even a carbon tax ${ }^{2}$ reaching $400 \$ / \mathrm{tCO}_{2}$ after 50 years (and tax revenues reach $23 \%$ of output) does not allow to avoid catastrophic climate change. A moderate initial $45 \$ / \mathrm{tCO}_{2}$ tax is possible with the same $\epsilon=3$ only in case of a low discount rate $\rho=0.001$; but this tax is not "temporary" since it increases through time and remains in place for more than a century and a half.

A low $10 \$ / \mathrm{tCO}_{2}$ initial tax decreasing over time is possible only with a high elasticity of substitution $\epsilon=10$ (see the table 1 in the Appendix). Surprisingly, although this low tax takes only a $0.5 \%$ of final output, the climate policy has a large negative impact on growth: the "slow growth transition phase" lasts forty years and starts with a $0.5 \%$ growth rate during the first decade ${ }^{3}$ (see the table 2 in the Appendix). This $75 \%$ reduction from the baseline growth rate ${ }^{4}$ is beyond the findings of the most pessimistic empirical models (Fisher et al., 2007) and would make climate policies politically unacceptable.

\footnotetext{
${ }^{2}$ The carbon tax is $\tau \hat{p}_{d} . Y_{d 0} / Y_{0} \cdot G D P_{0} / E_{0}$ (it is proportional to the input tax $\tau$ times the dirty good price). We use a world carbon intensity of GDP of $E_{0} / G D P_{0}=0.5 \mathrm{kCO}_{2} / \$$.

${ }^{3}$ Note that scenarios with different $\epsilon$ are hardly comparable. Indeed when $\epsilon$ varies, $A_{c}$ and $A_{d}$ need to be adjusted, so that initial states of the world are different which raises a methodological problem.

${ }^{4}$ This $2 \%$ world growth rate, a common assumption in modeling works for the long run, significantly departs from existing projections for the short and medium term: the IMF projects a $4.7 \%$ growth rate up to 2016 mainly because of the catch-up phase in emerging economies. We have no information about how the AABH model would behave with realistic growth rates. Starting from a higher baseline the growth rate with climate policy might be higher than $0.5 \%$ but baseline emissions would also be significantly higher in a first period which would magnify the decarbonization challenge and impose higher costs.
} 


\section{Implausible parameters choices}

\subsection{The elasticity of substitution}

The less pessimistic case relies on a high elasticity of substitution between clean and dirty inputs. Although Acemoglu et al. call for further research on the subject, they indicate that $\epsilon=10$ is "empirically plausible" given that "fossil and non fossil fuels should be close substitutes (at the very least, once non fossil fuels can be transported efficiently)". Possibly, all energy sources will be fairly substitutable, one day, as innovation widens the range of technological possibility. But this is not the case over the short or medium term, because neither gas nor coal can easily substitute for liquid fuels used in internal combustion engines. In addition to the historical fact that a $1 \%$ increase of the relative price of the fossil fuels never triggered a $10 \%$ decrease of their relative share in energy markets over a five year time period, such an optimistic value neglects the fact that the capital stock for large sections of the energy system lasts more than 50 years (Ha-Duong et al., 1997; Davis et al., 2010). The low short and medium term elasticity is due to the inertia of existing equipments and to the technical constraints imposed on the system by the energy carriers that transform primary into final energy and into specific end-use energy services.

There is an extensive literature on substituability by energy economists but a comparison of AABH assumptions with this literature is difficult because AABH focuses on primary energy instead of final energy ${ }^{5}$. Let us however try to link the elasticity of substitution of the AABH model with available data about price-elasticity. We suggest that, the AABH priceelasticity of demand for the dirty good calculated at fixed cost with other prices constant, is tantamount to the price-elasticity of consumer demand (at fixed income) for the dirty good ${ }^{6}$. With the AABH calibration, this gives a price-elasticity of demand for dirty good of -1.5 when $\epsilon=3$, and of -2.4 when $\epsilon=10$. Meta-analyses (Espey, 1998; Goodwin et al., 2004) of the price-elasticity of gasoline ${ }^{7}$ give a value situated between -0.3 and -0.6 . There are no such meta-analyses for coal but Dahl (1993) surveyed the sparse results and "find the evidence mixed but might be slightly more inclined to favor an inelastic price and income response". Since the price-elasticity is greater than -1 only when $\epsilon<1$, the elasticity of substitution is certainly below 1 .

With a more plausible value $\epsilon=0.5$, climate control (in the model) is impossible without halting long-term growth (see Figure 1 of the Appendix); the carbon tax begins at 350 and reaches $1000 \$ / \mathrm{tCO}_{2}$ in thirty years. The increase of total output is achieved more efficiently by a higher use of the - initially small - clean sector and researchers make higher profits in this sector. They would thus redirect their effort without subsidy. This raises the question about why, so far, the bulk of the research has occurred in the dirty sector.

\footnotetext{
${ }^{5}$ The elasticity of substitution between primary energies does not make sense technically because of heterogeneous efficiency in transformation channels between primary and final energy and because of the energy accounting conventions to build energy balances.

${ }^{6}$ In AABH, one final good is made out of two intermediate goods. We can alternatively have a consumer who directly consumes the intermediate goods; the final production function is then entailed in the utility of this alternative consumer. Standard algebra gives a price-elasticity of demand for dirty good $Y_{d}$ that is $-\epsilon-(1-\epsilon) /\left(1+\left(Y_{c} / Y_{d}\right)^{(\epsilon-1) / \epsilon}\right)$, the AABH calibration is $Y_{c} / Y_{d} \simeq 0.16$.

${ }^{7}$ which represents $30 \%$ of final energy consumption and $17 \%$ of $\mathrm{CO}_{2}$ emissions from the energy sector.
} 


\subsection{Climate module and available carbon budget}

The size of the carbon sinks in the AABH model, and thus the dynamics of the temperature increase $\Delta$ above pre-industrial levels, depends on the maximum possible increase $\Delta_{d i s}$ and the natural regeneration $\delta$. With the $\mathrm{AABH}$ calibration of these parameters, the temperature increase drops from $+1.5{ }^{\circ} \mathrm{C}$ to $+0{ }^{\circ} \mathrm{C}$ in eighty years. This contradicts lessons from climate modeling exercises which show that, even if we could stop now GHG emissions in the atmosphere, the global mean temperature would rise for several decades. From Figure 1 of (Acemoglu et al., 2011), the $\mathrm{CO}_{2}$ lifetime in the AABH scenarios appears to be situated in the 50 years' range. However physical evidence suggests lifetime ranges beyond 10000 years ${ }^{8}$.

Moreover, with $\Delta_{d i s}=+6{ }^{\circ} \mathrm{C}$, the $\mathrm{AABH}$ model assumes that carbon sinks are positive from $+0{ }^{\circ} \mathrm{C}$ to $+6{ }^{\circ} \mathrm{C}$. This neglects the fact that climate science suggests the likelihood of temperature thresholds beyond which ecosystems could abruptly switch from carbon sinks to carbon sources. These possible switches of possible "tipping elements" (Arctic sea-ice, Greenland ice sheet, Atlantic thermohaline circulation, Amazon rainforest) are located between $+2{ }^{\circ} \mathrm{C}$ and $+5{ }^{\circ} \mathrm{C}$ (Lenton et al., 2008).

Running the AABH model with more plausible climate parameters shrinks the carbon budget available to achieve climate control and increases the costs of achieving the decarbonization of the economy. Setting $\Delta_{d i s}$ at $+4{ }^{\circ} \mathrm{C}$ instead of $+6{ }^{\circ} \mathrm{C}$ halves the size of carbon sinks and, with $\epsilon=10$, the carbon tax starts around $40 \$ / \mathrm{tCO}_{2}$ and peaks at $100 \$ / \mathrm{tCO}_{2}$ in a century, whereas with $\epsilon=3$ the carbon tax starts around $200 \$ / \mathrm{tCO}_{2}$, reaches $600 \$ / \mathrm{tCO}_{2}$ in a century, but then keeps increasing.

\section{Structural problems of the AABH model}

\subsection{A misrepresentation of climate irreversibility}

In $\mathrm{AABH}$, the law-of-motion of $\mathrm{CO}_{2}$ concentrations is $C_{t+1}-C_{t}=\xi Y_{d t}+\delta\left(C_{t}-C_{d i s}\right)$. The first right hand term is emissions from dirty goods $Y_{d}$, the second is the natural removal of $\mathrm{CO}_{2}$ from the atmosphere. This removal mechanism is proportional to the difference between current concentration $C_{t}$ and disaster concentration $C_{d i s}$. The absorption capacity in the model never saturates, which allows a return to pre-industrial concentration levels in a short time period. In reality, the decay of $\mathrm{CO}_{2}$ exhibits a long tail because of interactions between various carbon pools with different characteristic times (Archer and Brovkin, 2008).

To check the consequences of this gross departure from climate science, we tested the behavior of the AABH model with a law-of-motion that follows the rule of thumb given by Archer (2005) to approximate the lifetime of anthropogenic $\mathrm{CO}_{2}$ : "300 years, plus $25 \%$ that lasts forever". The concentration $C_{t}$ of carbon is split between $C_{1, t}$, a naturally degradable concentration and $C_{2, t}$, a concentration that "lasts forever" ${ }^{9}: C_{2, t+1}=0.25 \xi Y_{d t}+C_{2, t}$. The carbon sinks follow a bell-shaped curve: natural regeneration is 0 when degradable concentration is at the pre-industrial equilibrium (280). It then increases to a peak and finally decreases and

\footnotetext{
${ }^{8}$ The lifetime of the $\mathrm{CO}_{2}$ concentration should not be confused with the atmospheric lifetime of individual atoms, see Archer et al. (2009) for a discussion.

${ }^{9}$ The lifetime of this stock is actually in the order of magnitude of a hundred thousand years.
} 
reaches 0 again when total concentration $C_{t}$ is equal to $C_{d i s}$, which we keep at the same value as in AABH. This can be written as: $C_{1, t+1}=0.75 \xi Y_{d t}+C_{1, t}-\delta\left(C_{d i s}-C_{1, t}-C_{2, t}\right)\left(C_{1, t}-280\right)$.

With this more scientifically based climate dynamics, carbon taxes are never null even in the most optimistic cases where the two inputs are strong substitutes. Independently of what we said about parameters choices, this confirms that the need for regulation is permanent and not transitory (see the comparison in figure 2 of the Appendix).

\subsection{An incomplete endogenous growth model}

In an endogenous growth model, the natural policy lever to reverse the above pessimistic conclusions would be to increase the amount of research. This could offset the long term adverse effect on the overall productivity of crowding out "normal" investment in promoting clean innovation. But the AABH is not a complete endogenous growth model. The long term growth is exogenous, there is a fixed number of researchers and the research activity demands no other component of the final good than the researchers' consumption. Technical change is thus a costless manna from researchers substituted to the manna from heaven in the Solowian models. The AABH planner allocates the researchers between sectors but misses one degree of freedom, the global amount of research.

To clarify the trade-off between consumption and savings or between investing in research and production capacities, it is necessary, ceteris paribus, to allow a reallocation of labor between production and research and to endogenize the level of research. Total labor, normalized to 1, can now be allocated in clean or dirty production and in clean or dirty research: $L_{c t}+L_{d t}+s_{c t}+s_{d t} \leq 1$. At the optimum point, allocation is governed by an indifference relation:

$$
\lambda_{t} \hat{p}_{c t}(1-\alpha) \frac{Y_{c t}}{L_{c t}}=\mu_{c t} \gamma \eta_{c} A_{c, t-1}
$$

The left-hand side is the shadow-value of consumption $\left(\lambda_{t}\right)$ times the marginal production of a worker $\left(\hat{p}_{c t}(1-\alpha) \frac{Y_{c t}}{L_{c t}}\right)$ and the right-hand side is the shadow-value of productivity $\left(\mu_{c t}\right)$ time the marginal increase of productivity of a researcher $\left(\gamma \eta_{c} A_{c, t-1}\right)$. From this relation, when $\epsilon>1$, we are able to derive an implicit equation for the optimal proportion $s_{c}$ of researchers (see A.2 of the Appendix for the derivation and numerical applications). This equation can be used in two ways:

(1) fix long-term growth $g$, solve for the optimal level $s_{c}$, and then deduce the researchto-growth ratio. If the optimal long-term growth rate is fixed at $2 \%$ per year, with a $1.5 \%$ pure-time preference, the optimal share $s_{c}$ is $37 \%$, meaning that almost two-fifth of the population should be composed of researchers. But, if we apply this research-to-growth ratio to a current share of, let's say, $10 \%$, then the achievable long-term growth rate is a low $0.55 \%$ in laissez-faire economies.

(2) Alternatively, if we suppose that $10 \%$ of population being currently engaged in research gives rise to a $2 \%$ growth rate, this fixes the research-to-growth ratio. The central planner can modify the level of research to the optimum $s_{c}=47 \%$, calculated with the equation. This results in an optimal growth rate of $8.2 \%$.

Thus, none of the numerical experiments conducted without the separation between workers and researchers delivers plausible orders of magnitude. This is indicative of a structural 
problem. In complete endogenous growth models, even without explicit physical capital, investments are often incorporated in the form of accumulated knowledge and an interest rate governs households' trade-off between consumption and savings, and the allocation of savings to research and physical capital. In such models, the free entry in research imposes a no-profit condition and determines the interest rate ${ }^{10}$. All these mechanisms are frozen in AABH by a fixed number of researchers, no savings and no interest rate.

Thanks to this separation between workers and researchers, the level of research efforts can be arbitrarily selected without the consistency check imposed by a complete endogenous growth model. This in turn means that there is no way of controlling the relative productivity of research vis-à-vis labor. This raises concerns about the value of a model where assumptions about the social return to research does not elucidate the relative contribution of innovation as a substitute for carbon taxes.

\section{Conclusion}

Acemoglu et al. fail to support their claim that innovation subsidies and a low carbon tax would allow to meet ambitious climate mitigation objectives without large negative impacts on growth. Simulations conducted with the same model in fact show the opposite, except in case of implausibly optimistic parameters regarding the carbon budget and the elasticity of substitution between clean and dirty technologies. We explain that this model relies on very restrictive structural assumptions that make it impossible to detect levers to decouple carbon emissions and economic growth without placing a high burden on current generations.

We can identify three avenues for removing these restrictive structural choices. The first is to capture some important channels through which the ideas of researchers ultimately become real products through engineering, testing, scale-up and marketing ${ }^{11}$; this requires a model that, in contrast with that of Acemoglu et al., includes productive capital and learningby-doing mechanisms. The second is to analyze the up-front investment risks at all the stages of the innovation chain and those resulting from the controversial nature of the division line between "clean" and "dirty" technologies (as in the case of large scale biofuels, nuclear energy for example). The third is to identify to which extent a shift toward a new growth path must be achieved with the existing best available technologies; for example avoiding a bifurcation towards a carbon intensive pathway in emerging economies depends on mobilizing these techniques in transportation and energy infrastructures that will be built in the following two decades.

The purpose of following these avenues is to incorporate, in alternative modeling frameworks, mechanisms that are absent in the AABH model. Building on the large body of literature in the field, this would allow to better understand how these mechanisms are activated by subsidizing innovation and levying carbon taxes, with or without complementary policies, in order to achieve an economically and environmentally sustainable growth path.

\footnotetext{
${ }^{10} \mathrm{~A}$ symptom of the incompleteness of the AABH model is that it allows a user to select arbitrarily the discount rate $\rho$. Actually changing the $\rho$ implies, for a given growth rate, a change in the productivity of capital or the elasticity of the marginal utility of consumption.

${ }^{11}$ See Dosi (1982, 1988); Arthur (1989); Goulder and Schneider (1999); Arrow (1962); Grübler et al. (2002).
} 


\section{References}

Acemoglu, D., P. Aghion, L. Burzstyn, and D. Hemous (2011). The Environment and Directed Technical Change. The American Economic Review, to be published.

Archer, D. (2005). Fate of fossil fuel $\mathrm{CO}_{2}$ in geologic time. Journal of Geophysical Research 110 (C09S05). doi:10.1029/2004JC002625.

Archer, D. and V. Brovkin (2008). The millennial atmospheric lifetime of anthropogenic $\mathrm{CO}_{2}$. Climatic Change 90(3), 283-297.

Archer, D., M. Eby, V. Brovkin, A. Ridgwell, L. Cao, U. Mikolajewicz, K. Caldeira, K. Matsumoto, G. Munhoven, A. Montenegro, et al. (2009). Atmospheric lifetime of fossil fuel carbon dioxide. Annual Review of Earth and Planetary Sciences 37, 117-134.

Arrow, K. J. (1962). The economic implications of learning by doing. The Review of Economic Studies 29(3), 155-173.

Arthur, W. (1989). Competing technologies, increasing returns, and lock-in by historical events. The economic journal $99(394), 116-131$.

Dahl, C. (1993). A survey of energy demand elasticities in support of the development of the nems. Technical report, United States Department of Energy.

Davis, S. et al. (2010). Future CO2 Emissions and Climate Change from existing energy infrastructure. Science 329, 1330-1333.

Dosi, G. (1982). Technological paradigms and technological trajectories:: A suggested interpretation of the determinants and directions of technical change. Research policy 11(3), $147-162$.

Dosi, G. (1988). Sources, procedures, and microeconomic effects of innovation. Journal of economic literature $26(3), 1120-1171$.

Espey, M. (1998). Gasoline demand revisited: an international meta-analysis of elasticities. Energy Economics 20, 273-296.

Fischer, C. and R. Newell (2008). Environmental and technology policies for climate mitigation. Journal of environmental economics and management 55(2), 142-162.

Fisher, B. S., N. Nakicenovic, et al. (2007). Issues related to mitigation in the long term context. See Metz et al. (2007), pp. 169-250.

Gerlagh, R. (2008). A climate-change policy induced shift from innovations in carbon-energy production to carbon-energy savings. Energy Economics 30(2), 425-448.

Goodwin, P., J. Dargay, and M. Hanly (2004). Elasticities of road traffic and fuel consumption with respect to price and income: a review. Transport Reviews 24(3), 275-292. 
Goulder, L. H. and S. H. Schneider (1999). Induced technological change and the attractiveness of co2 abatement policies. Resource and Energy Economics 21(3-4), 211 - 253.

Grübler, A., N. Nakicenovic, and W. D. Nordhaus (Eds.) (2002). Technological change and the environment. Washingtion: Resources for the Future.

Gupta, S., D. Tirpak, et al. (2007). Policies, instruments and co-operative arrangements. See Metz et al. (2007), pp. 745-807.

Ha-Duong, M., M. Grubb, and J.-C. Hourcade (1997). Influence of socioeconomic inertia and uncertainty on optimal $\mathrm{CO}_{2}$-emission abatement. Nature 390 (6657), 270-273.

Hourcade, J.-C. et al. (1995). Estimating the costs of mitigating greenhouse gases. In P. Bruce, H. Lee, and E. Haites (Eds.), Climate change 1995. Economic and social dimensions of climate change. Contribution of Working Group III to the Second Assessment Report of the Intergovernmental Panel on Climate Change., pp. 263-296. Cambridge University Press.

Hourcade, J.-C., P. Shukla, et al. (2001). Global, regional and national costs and co-benefits of mitigation. In B. Metz, O. Davidson, R. Swart, and J. Pan (Eds.), Climate Change 2001: Mitigation. Contribution of Working Group III to the Third Assessment Report of the Intergovernmental Panel on Climate Change, pp. 499-559. Cambridge University Press.

Lenton, T., H. Held, E. Kriegler, J. Hall, W. Lucht, S. Rahmstorf, and H. Schellnhuber (2008). Tipping elements in the Earth's climate system. Proceedings of the National Academy of Sciences 105(6), 1786-1793.

Metz, B., O. Davidson, P. Bosch, R. Dave, and L. Meyer (Eds.) (2007). Climate Change 200\%: Mitigation. Contribution of Working Group III to the Fourth Assessment Report of the Intergovernmental Panel on Climate Change. Cambridge University Press.

Schmidt, R. and R. Marschinski (2009). A model of technological breakthrough in the renewable energy sector. Ecological Economics 69(2), 435-444. 


\section{A Appendix}

\section{A.1 Results of the AABH model}

Table 1: Carbon tax $\left(\$ / \mathrm{tCO}_{2}\right)$ in the AABH model

\begin{tabular}{l|c|c|c|c|c|c|c} 
Years & 5 & 25 & 50 & 75 & 100 & 125 & 150 \\
\hline$\epsilon=10, \rho=0.015$ & 10 & 8.6 & 6.4 & 2.6 & 0 & 0 & 0 \\
$\epsilon=3, \rho=0.001$ & 47 & 48 & 52 & 60 & 74 & 92 & 110 \\
$\epsilon=3, \rho=0.001$ & 75 & 160 & 400 & 490 & 610 & 800 & 1100
\end{tabular}

Table 2: Growth rate of total production in the AABH model

\begin{tabular}{l|c|c|c|c|c|c|c|c} 
Years & 5 & 10 & 15 & 20 & 25 & 50 & 75 & 100 \\
\hline$\epsilon=10, \rho=0.015$ & 0.36 & 0.65 & 1.0 & 1.2 & 1.5 & 2.0 & 2.0 & 2.0 \\
$\epsilon=3, \rho=0.001$ & 0.25 & 0.54 & 0.59 & 0.65 & 0.71 & 1.0 & 1.3 & 1.6
\end{tabular}

\section{A.2 Calculation of the optimal level of research}

In the optimal programme, we remove the separation between researchers and workers. We allow labor to be allocated either in production or in research: $L_{c t}+L_{d t}+s_{c t}+s_{d t} \leq 1$ (the total labor is normalized to 1 ).

At the optimum, the shadow value of a unit of worker in the clean sector is the same as a shadow value of a unit of clean researcher. Thus

$$
\lambda_{t} \hat{p}_{c t}(1-\alpha) \frac{Y_{c t}}{L_{c t}}=\mu_{c t} \gamma \eta_{c} A_{c, t-1}
$$

where $\lambda_{t}$ is the shadow value of consumption and $\mu_{c t}$ is the shadow value of productivity. The equation for $\mu_{c t}$ is still equation (A.13) of (Acemoglu et al., 2011):

$$
\mu_{c t}=\lambda_{t}\left(\frac{\alpha}{\psi}\right)^{\frac{\alpha}{1-\alpha}}(1-\alpha) \hat{p}_{c t}^{\frac{1}{1-\alpha}} L_{c t}+\left(1+\gamma \eta_{c} s_{c, t+1}\right) \mu_{c, t+1}
$$

From now on, we concentrate on the case $\epsilon>1$. We define $\tilde{\mu}_{c t}=\mu_{c t} /\left(\lambda_{t}\left(\frac{\alpha}{\psi}\right)^{\frac{\alpha}{1-\alpha}}(1-\right.$ $\left.\alpha) \hat{p}_{c t}^{\frac{1}{1-\alpha}} L_{c t}\right)$. The equation is thus:

$$
\tilde{\mu}_{c t}=1+\frac{\lambda_{t+1}}{\lambda_{t}}\left(\frac{\hat{p}_{c, t+1}}{\hat{p}_{c t}}\right)^{\frac{1}{1-\alpha}} \frac{L_{c, t+1}}{L_{c t}}\left(1+\gamma \eta_{c} s_{c, t+1}\right) \tilde{\mu}_{c, t+1}
$$

As research is totally devoted to the clean sector, $A_{c t} \rightarrow+\infty$, so, because $\epsilon>1, \frac{\hat{p}_{c, t+1}}{\hat{p}_{c t}} \sim 1$ and also $\frac{L_{c, t+1}}{L_{c t}} \sim 1$. Let us denote $s_{c}$ the limit of $s_{c t}$. Then $\frac{\lambda_{t+1}}{\lambda_{t}} \sim \frac{\left(1+\gamma \eta_{c} s_{c}\right)^{-\sigma}}{1+\rho}$. So $\tilde{\mu}_{c t} \sim$ $1+\frac{\left(1+\gamma \eta_{c} s_{c}\right)^{1-\sigma}}{1+\rho} \tilde{\mu}_{c, t+1}$, thus: 


$$
\tilde{\mu}_{c t} \sim \frac{1}{1-\frac{\left(1+\gamma \eta_{c} s_{c}\right)^{1-\sigma}}{1+\rho}}
$$

As $Y_{c t}=\left(\frac{\alpha}{\psi} \hat{p}_{c t}\right)^{\frac{\alpha}{1-\alpha}} A_{c t} L_{c t}$ (equation (A.12) of (Acemoglu et al., 2011)) and $A_{c, t-1}=$ $A_{c t} /\left(1+\gamma \eta_{c} s_{c t}\right)$ (equation (11) of (Acemoglu et al., 2011)), equation (A.1) becomes, after simplification

$$
1 \sim \frac{L_{c t}}{1-\frac{\left(1+\gamma \eta_{c} s_{c}\right)^{1-\sigma}}{1+\rho}} \frac{\gamma \eta_{c}}{1+\gamma \eta_{c} s_{c t}}
$$

Because $L_{c t} \sim 1-s_{c}$ and $s_{c t} \sim s_{c}$, we thus obtain an equality between limits, which writes, after rearrangement:

$$
1-\frac{\left(1+\gamma \eta_{c} s_{c}\right)^{1-\sigma}}{1+\rho}=\frac{\gamma \eta_{c}\left(1-s_{c}\right)}{1+\gamma \eta_{c} s_{c}}
$$

This is the implicit equation (valid when $\epsilon>1$ between the optimal proportion $s_{c}, \rho$ is the pure-time preference, the research-to-growth ratio $\gamma \eta_{c}$, the inverse $\sigma$ of the elasticity of intertemporal substitution. The (optimal) long-term growth rate is $g=\gamma \eta_{c} s_{c}$.

In the text, we use this equation in two ways.

In the first case, we fix the long-term growth rate $g=2 \%$. The implicit equation becomes:

$$
1-\frac{(1+g)^{1-\sigma}}{1+\rho}=\frac{g / s_{c} \cdot\left(1-s_{c}\right)}{1+g}
$$

We solve the equation, find $s_{c}=37 \%$, and thus a research-to-growth ratio $\gamma \eta_{c}$. With this research-to-growth ratio, a more realistic $10 \%$ of population currently engaged in research give rise only to a $0.55 \%$ growth rate.

In the second case, we fix $\gamma \eta_{c}$, considering that, in laissez-faire economies, $10 \%$ of population currently engaged in research give rise to a $2 \%$ growth rate. We solve the implicit equation, and find $s_{c}=47 \%$, and thus an optimal growth rate $g=8.2 \%$.

For all the numerical applications, one has to keep in mind that the model is not timescale invariant (because of discrete time). So in the calculations, the values of growth rate and pure-time preference have to be expressed in per five year (because the time-period lasts five year) not in per year. The latter unit is however used to display the result; for example, one has to set $1+g=1.02^{5}=1.104$ and $1+\rho=1.015^{5}=1.077$.

\section{A.3 Comparative exercises with the AABH model}



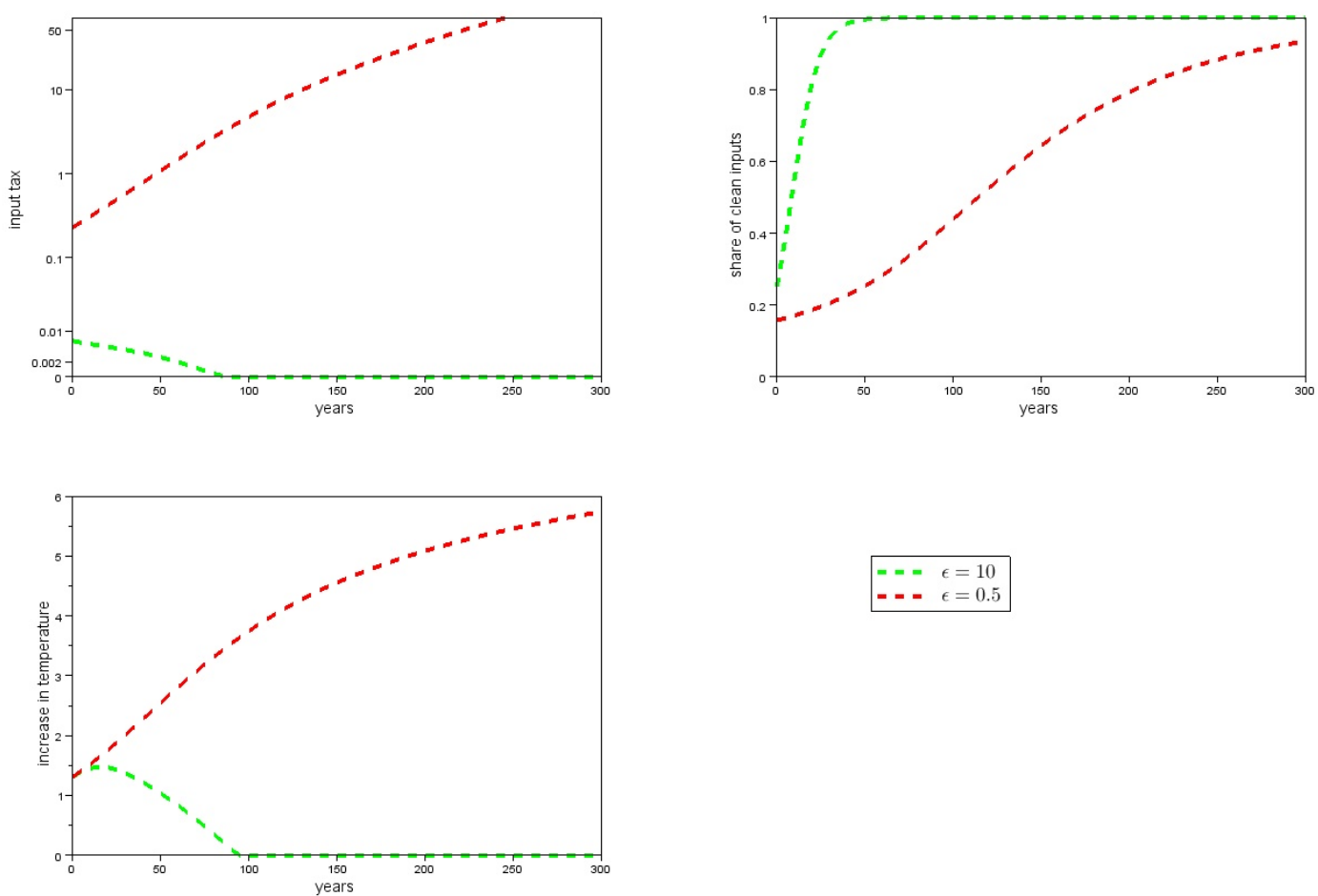

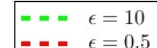

Figure 1: Comparisons of the AABH model with $\rho=0.015$ and $\epsilon=10$ (strong substitutes) or $\epsilon=0.5$ (weak substitutes) 

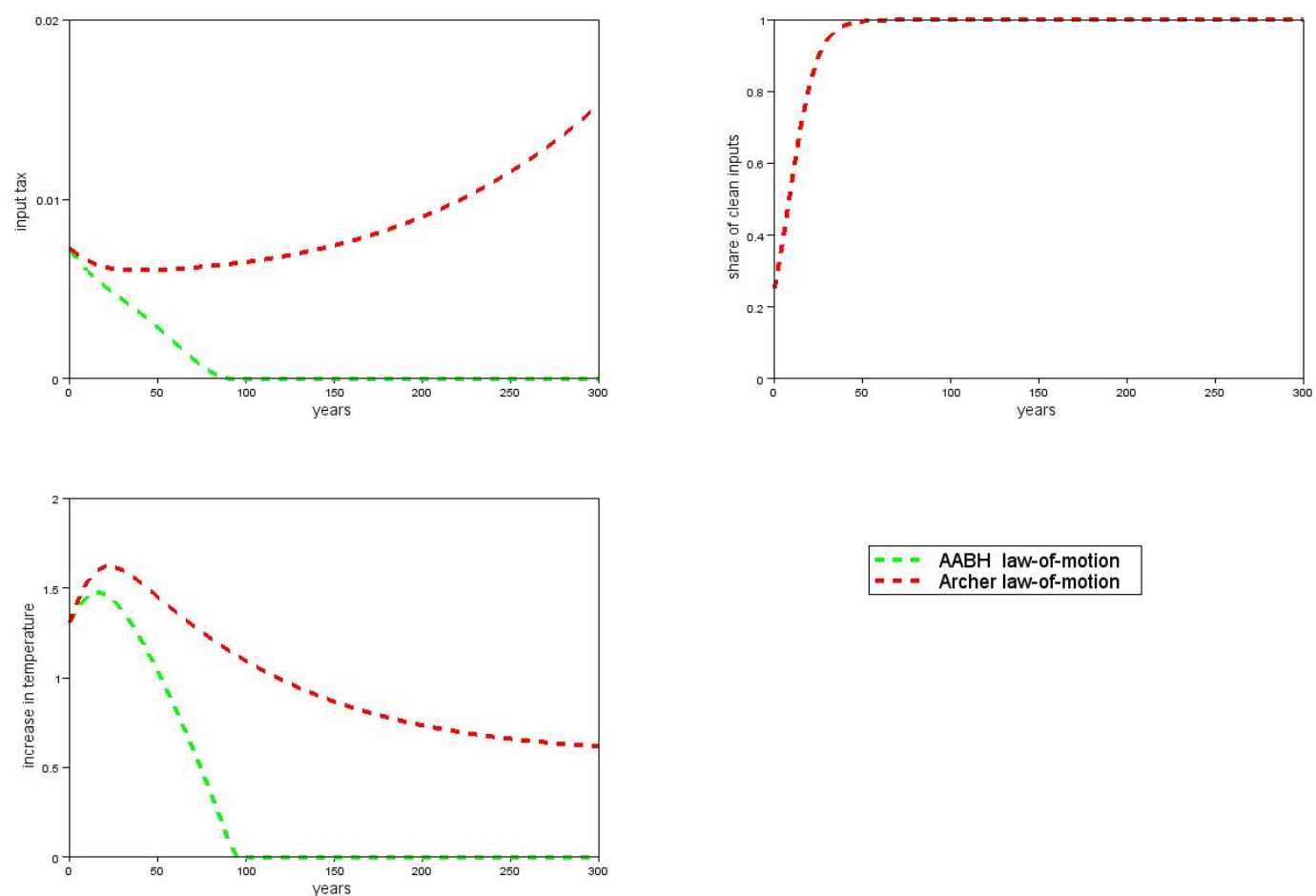

$=--$ AABH law-of-motion Archer law-of-motion

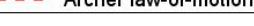

Figure 2: Comparison of the AABH and Archer law-of-motion, when $\epsilon=10, \rho=0.015$ 